\title{
Surgery sends futures to the past
}

\author{
Martin Riegler
}

C Springer-Verlag GmbH Austria, part of Springer Nature 2018

Dear reader,

Welcome to this issue of European Surgery presenting the fragments of highly motivated projects, works, and studies in various fields of modern surgery and medicine. The spectrum range includes minimally invasive, oncological, colorectal, esophageal, endocrine, and vascular surgery. I hope the articles foster a positive reasoning and are of value for your daily academic and routine clinical work.

\section{Summer was beautiful}

Following a great and hot summer holiday, you may be very motivated with plans for the upcoming year: You may wish to implement new ideas for the diagnosis and therapy of diseases. You may consider starting novel projects aiming to examine significant issues for a better understanding of the management of benign and malignant disease. You may, at least in part, hope to make new friends and hesitate to expose yourself to negative competition, vibrations, and communication at home, in your private life, and at work. You hope to learn from the mistakes of others, and that you may not be forced to repeat these errors, for the benefit of your patients, friends, and families. The sun was shining and the weather was sweet. Clear blue skies over the umbrella of your emotions, desires, and dreams. You may recall the holiday season and all the perceptions you were allowed to borrow from the universe. You may remember the meaningful, beautiful, relaxing times that you shared with your families and friends by the sea, at a lake in the Alps, the nourishing fruits of an island in the Indian Ocean,

Doz. Dr. M. Riegler $(\bowtie)$

Reflux Medical, Mariannengassse 10/9, 1090 Vienna, Austria martin.riegler@refluxmedical.com the dancing atmosphere of a Jamaican reggae roots landscape, cigar-consuming banana republic experience visiting Cuba, Far East Indonesia with its typical tea party-shadowed smell of concentrated thoughts, hopes, and beliefs, the unique walls of light in Middle East deserts, or even witnessing the communication between ancient and modern times in Egypt, Israel, Turkey, Greece, Italy, eastern, middle central, western, and northern Europe, North, Mid and South America (the Americas), and Africa. Gratefulness steers consciousness. Will to power drives perception into being. You will never forget this touching sunrise, sunset, moonrise, moonset, break of dawn, and the atmosphere where it all began. Once upon a time it became clear. It happens all for you to foster new energy and motivation for the future. At this point you may have asked yourself: What is now? What is the importance of a moment? What has remained from my holidays? What could I have gained from my experiences? Could I be loved? Could I be wanted, liked at all? Would that be important to know? Have you been swimming in the ocean of emotion covered by the multi-plurabello spectrum of atmospheres capable of being aware and open with your mind? Have you been happy to say, "I am as I am and I like the way that I am?" European Surgery aims to address the important and essential questions in medicine. Therefore, we do not hesitate to ask: What is now? And: What is it all about? In order to address these questions, it is important to understand the mechanisms underlying the processing of a given perception. Here we go!

\section{Perception and space time}

In recent issues of European Surgery we aimed to examine how perception works and how processing and translation of perception into treatable signs fosters emotions and depends on atmosphere, mood, and 


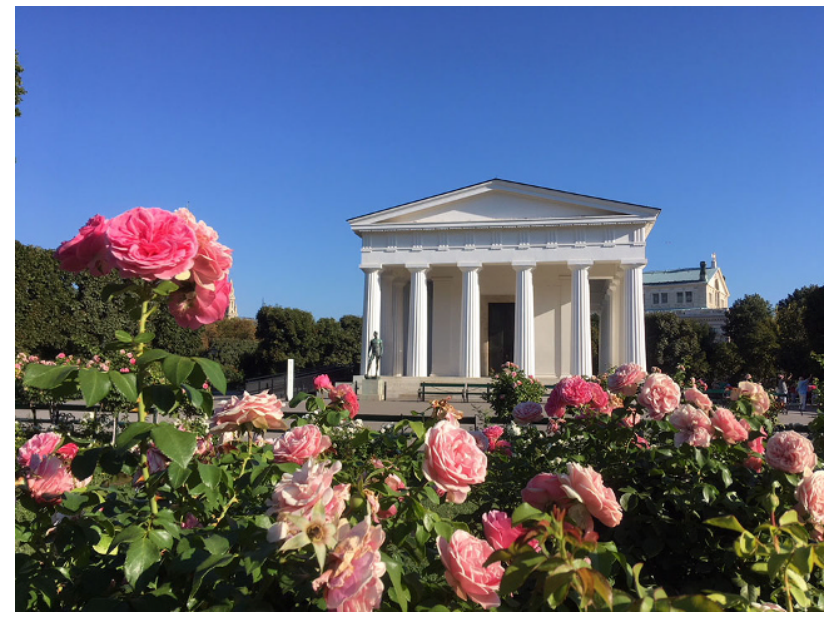

Fig. 1 A nineteenth century remake of an ancient Greek temple symbolizing the major themes of the myth of mankind, as outlined in the text. The temple mirrors the interaction between man, reasoning, cosmic powers, and being. Image obtained in the People's Garden Vienna, Austria

temper. Finally, we felt that reasoning, perception, thinking, and atmosphere arise as manifestations of being (Fig. 1). What remains to be questioned is the role of space time within this conduct of reasoning and matter of fact. It seems that emotion counts and drives hope and belief.

Space time represents a valuable model serving a better understanding of cosmic and quantum-based phenomena (Fig. 2). Thus, it also helps to explain surgery. As suggested in a recent issue of European Surgery, an individual particle neither shares space nor time. In line with the concepts of relativity and quantum physics, space time evolves as the consequence of communication, interaction, and exchange of information between given quanta of energy. As

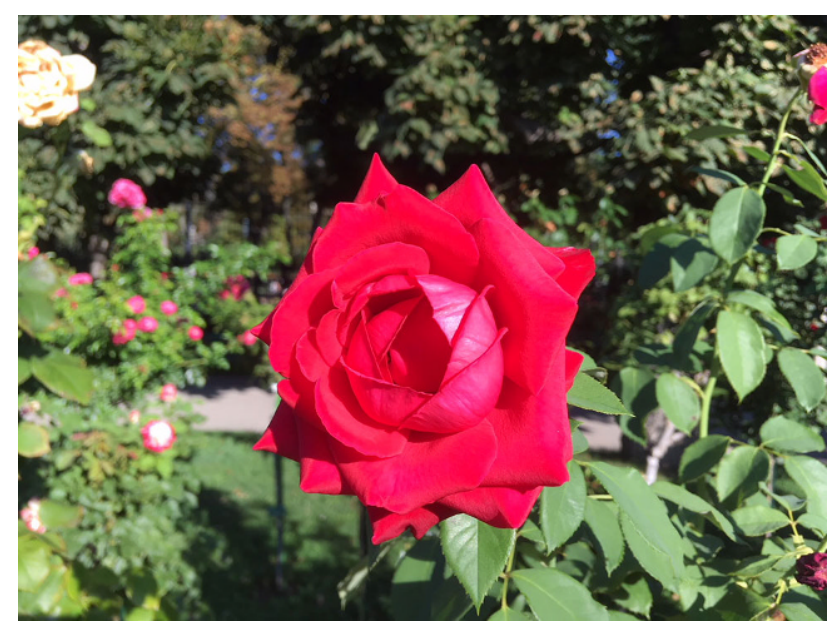

Fig. 3 The rose opens toward the light. This observation reflects the creation of consciousness, emotion, and being due to its beautiful interplay with space time and the heavens, as described in the text

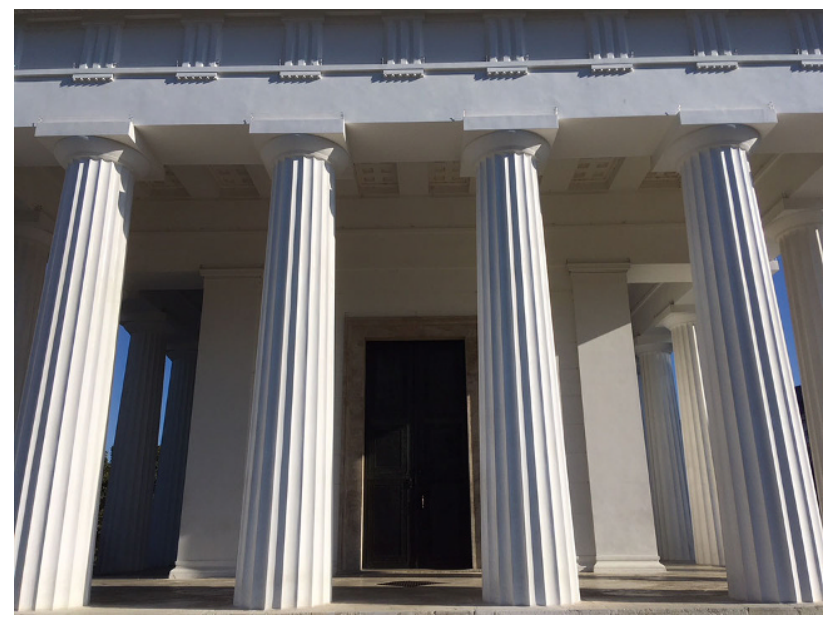

Fig. 2 Remake of an ancient Greek temple. The geometry and structure of the temple symbolize the connections between the heavens, the earth, and the interplay between sensations that we are allowed to see (perceive; the pillars) and the intersections between the pillars that we are not allowed to perceive (i. e., the so-called nothing according to philosophical concepts)

such, the exchange of signs and coded information creates space time. Thus, space time does not exist without interaction-there is no space time without interaction (Fig. 3). The question remains of whether space time exists without us, without people who are capable of observing space time phenomena.

Furthermore, and this has been well adopted by the outstanding works of Umberto Eco, the exchange of signs and information does not only create space time, the exchange of information represents the fundamental manifestation of space time, i.e., the exchange of information makes up and equals space time. Therefore, phenomena are manifestations of space time and may be perceivable to us (truth) or not ("nothing"; Figs. 1 and 2). Man invented a large and fascinating spectrum of technologies and concepts of reasoning (philosophical systems) for the translation and processing of manifestations of perceptions. Basically, all phenomena from the macro- and microcosmos enter our perception in the form of quantum-based waves and fields. Energy is the gatekeeper, maker, and revealer of the quantum world. There, energies are translated into perceivable phenomena and signs by translators. As such, electromagnetic fields manifest in the form of sound, images, colors, vibrations, and smell and contribute toward stimulating our mood, our atmosphere, our temper. In addition, atmosphere decides on the interpretation of these phenomena, i. e., whether we think that the perceptions are good, bad, positive, negative, comforting etc. Forms of atmosphere created by our consciousness include love, hate, greed, envy, hunger, hope, belief, gratitude, humility, sorrow, pain, desire, justice, morals, knowledge, and despair. It is hard to tell what comes first: the atmosphere, which decides on the valuation of a particular perception (good, bad etc.) or 
the phenomena, which trigger the atmosphere, which influences a given interpretation. The state of affairs are emotions. Finally, it may be that we cannot differentiate between the contributions of atmosphere, phenomena, and their specific interactions. As a consequence, it seems justified to argue that atmosphere, phenomena, and their interpretations are the same and equal being. Here, we arrive at the point where the Vedas, the old Egyptian pyramid texts, and the ancient Greek thinkers started from: conceptually, being and thinking are the same. I am that I am ("Joker Smoker," Peter Tosh, Jamaica). This understanding is the basis and the origin and the main theme of myth and story-telling. You cannot run away from yourself ("Joker Smoker," Bob Marley, Jamaica). In contrast to our modern scientific language, the ancient myth operated with complex systems of signs, symbols, and representations, the understanding of which became lost and vanished over many thousand years. What remained was a feeling, a taste, an atmosphere, which drives our interest to get involved in these old myths, texts, stories, and legends. Somehow man reasons that these stories represent an important legacy and incorporate fundamental information and knowledge for us. Furthermore, our science, our technologies represent the modern form of myth and story-telling. Why? Because it is all about us, you, and me, dear reader! Once upon a time, human beings created an idea and constructed the pyramids all over the world; today, and driven by the same enthusiasm, i.e., the will to power, man can circumnavigate our globe at $27,000 \mathrm{~km} / \mathrm{h}$. The ISS takes about $90 \mathrm{~min}$ for one complete circuit around our beautiful globe. Take your time to see the wonderful images that are obtained from the ISS. Our globe is a wonderful, beautiful, amazing, awesome pearl of the universe. It is the only place in the universe where we are allowed to gain and make observations. This myth shows how unimportant we are, how small we are, or unnecessary we are and that we should treat the world, our nature, and ourselves with respect, tolerance, gratitude, and humility.

\section{Fun do $2 \mathrm{U}$}

Walk on your globe as if you were performing a gentle dissection adjacent to dangerous structures and tissues, i.e., the aorta, the heart, the pelvic vessels, the facial nerves etc. These are the lessons that all myths are teaching us and that all myths have in common: Nothing should be taken for granted, all is borrowed, even if you are chosen to "possess" it. Therefore, the myth of mankind shares this essential and greatly important and highly fundamental and essential piece of truth! Irrespective of the form of myth-telling (physics, medicine, astronomy, logics, ethics) the essential information of the myth reads: Stay away from greed, envy, hate, hunger, war, because it destroys you, eliminates you, cuts you off from the harmony and the balance and makes you sick! Disease represents dysbalance. Essentially, a disease aims to teach the patient to search for regaining balance and harmony and to stay away from negative vibrations. As such, the so-called psychosomatic diseases represent a special form of myth-telling. However, the tune is not heard, the sound is not adequately translated and interpreted into action, and therefore we have to follow the consequences of will to power. These consequences are well known and fill the pages of analogue and digital newspapers, the frames of TV shows, and breaking news: Man serves the will to power, it seems that this is the single and only meaning and justification of human existence. Could there be a stepping out? Would there be short moments of escape? May there be space time for utopia? And here we focus directly on a very old tradition. Here we go: How should we bridge our existence without getting involved in the will to power? Fun do $2 \mathrm{U}$ !

\section{The eye of our future}

The eye of Horus represents a fundamental, extremely important icon of old Egyptian wisdom.

In addition to symbolizing the cosmic interplay between the sun and the phases of the moon, the Horus eye mirrors the moment, the momentum (German: Augenblick), the actual instant and content of perception. Thus, the Horus eye symbolizes reasoning and being. However, perception takes time, needs time for nerve activity-based transmission, exchange, and processing of information until the full and complete creation of a given perception arises in the front of our "inner" eye (of Horus). And, therefore, any perception reads the past. Any perception represents a myth of the past, may it be light years, years, hours, minutes, seconds, or milli- or nanoseconds, it always represents a piece of the past. The future is generated based on information. The future results from the processing of information generated during the conduct of reasoning. In line with the aforementioned considerations, the construction of the future consumes space time and thus also reads the past. As such, you may come up with the following idea: There exists no present and future, it all represents the past, signs from the past, information and atmosphere from the past (years, minutes, seconds, nanoseconds etc.). Present is past, future has past. Past creates being. A clarification remains to be considered.

There is no doubt that past, present, and future exist as valuable concepts and are of extreme practical importance for our daily life including communication and the exchange of information. Therefore, the differentiation between past, present, and future is essential for planning surgeries, diagnostic procedures, and therapies. Furthermore, the terms are the basis for scientific work, publishing, and the design of academic trials. 
However, due to nerve cell physiology, the transmission and translation of phenomena into perceivable signs takes time. As a consequence, we always perceive information from the past, even if we talk about imaginings, phantasies, and ideas regarding our future, we recall (unknown) time gaps between the generation and the perception of a given sign. There is no "now" without containing a past. Therefore, essentially, all perception originates in the past, all perception (inner and outer world) is past. Consequently, consciousness and all our perceptions from the inner and the outer world and most importantly the will to power underly the character of having been. And here we touch upon the very essence of the myth of man: It traces back to the origins of our perceptions-phenomenologically the character of having been drives the world. Even the will to power follows the character of having been. As a consequence, surgery always cuts the past, treats the past, even a future-directed prognosis reads the past. Future is history and comes at the beginning, comes first. This is the very truth underlying every myth, even medicine, surgery, oncology, and you, reading these lines. There always exists a gap of milliseconds between the reading and the perception and the processing and the understanding of the words incorporated in these lines. As you read the term "now" you know that it is a trace from your past. Every "now" is a past, every future is a past, all is past, all has past, and this seems to be the clarification of any perception. It all shares the character of having been.

Modern surgery happens within the enormous tensions of the global, quantum-web-based stream of continuously evolving novel information and requires well-tuned multitasking decision-making to keep up with the rapid speed at which changes are taking place and how these changes are continuously creating new realities, i.e., new variations of the essence. These developments create a new generation of surgeons who are forced to become an application of the quantumweb-based system (QWBS). Using their cell phones, tablets, computers, and digital watches, modern surgeons are continuously perceiving, processing, and emitting data, which in turn feed the database of the World Wide Web and thus contribute to the constant increase of digital information and knowledge. These developments enrich our QWBS, our lives, contribute toward increasing our life quality, our life-supporting management system (health care, you care) and wellbeing and it seems that we cannot live without these novel technologies. Therefore, these new technologies allow for the development of new techniques that in turn help expand the armamentarium of surgery, oncology, and patient care (who cares about you?). There would be no minimally invasive, computerbased, remote-targeted, and tailored surgeries of the abdomen, thorax, thyroid, kidneys, adrenals, breast, and axilla without the medical applications of the QWBS. There would be no hesitation against brain transplantation without the QWBS. The QWBS helps increase the life expectancy of modern women and men and very soon, dear reader of these lines, those who are born today (2018!) will reach a mean of 100 years of age \pm coins of an inch of a pound to Ezra with Joyce of joy double ham humbling hero of history. As such the QWBS turns out to be the new major invention of mankind, the new god, religion, and despotism created by, for, and due to man in order to follow the very essence and reason of life, perception, and atmosphere: the will to power. Could it be that this also creates a new form of despotism, whose slaves we are going to be? Or already are? At present? Today? As you read these lines? Whom do you serve, without knowing? Do you want, do you wish to know?

Conceptually, despotism creates idea-based systems, invented by man and aiming to justify the increase of power and control over people (masses, majorities, instruments of power). Despotism follows the concept of the will to power and helps to gain control over men and women, children, and their lives. As such, despotism serves those who are in power. Propaganda serves to hide this aspect. Even the tumor aims to gain control over the organism it selected for manifestation. Oncology hides behind this mask. The most important day in our life: death unmasks. Well-known forms of despotism are any kinds of politics, religions, beliefs and many different forms of industries including the car, arms, aviation, computer, tourism, beauty, fashion, pharmaceutical, medical, entertainment, and communication industry and science. Thus, it seems that we cannot escape to serve any unhidden despotism. It seems that there is no life without despotism. Could it be that nature itself, i.e., that part of the universe that has not been invented by man, also underlies some kind and form of despotism, will to power? Or do we interpret the "will to power" concept into our perceptions aiming to find a better explanation? Could it be that each of us serves one or multiple industries without knowing it? Could it be that we serve forms of despotism without knowing it? Without perceiving it? Could it be that statements coined by these forms of despotism do not reflect the truth at all? Could it be that there exists no truth? Could it be that we are misused believers and hopers? Could it be that we are applications nourishing the profits of all these industries without being aware of it? Could it be that there is no way out of this dilemma? Whose fault is it? Is it a fault? Can these insecurities be prevented? In line with these considerations about the processing and translation of perceptions it seems reasonable and justified to assume that there exists no truth, that we are not enabled to know the truth, and what we care about are simply approximations of the state of affairs behind our perceptions. Man invented god, money, weapons, great medicine and used it to serve the will to power, i.e., being. Is it possible that we escape forms, kinds, and revelations of despotism? Is it possible to live, 
exist without serving any kind of despotism? Which are the forms and classes of despotism that you want to get rid of first? Do you still want to be exploited by politics, power games, consumerism, religion? Which may be the most valuable form for designing your individual form of existence? What is the difference between the "must have" and the "want to have"? Is there a way to overcome the will to power? Is there a type of thinker, who may be, at least for short periods of time, capable of overcoming the will to power? To overcome the greed, hate, and hunger created by the will to power? Is it possible to think that a modern kind of personality would be capable of outbalancing the will to power, to resist being fed, directed, organized by the will to power? It seems that we all possess the will to power and that the will to power drives and equals reasoning and being. Here we step back for a moment and take a break. Next, we examine the qualities of a personality that may be capable of outbalancing the will to power.

In line with the recent editorials of European Surgery, the existence of such a character would be possible and would include the following qualities: gratitude, open-minded twisted reasoning, and, most importantly, tolerance and discipline. This personality would have to follow strict, clear-cut lifestyle guidelines. This person would have to follow a disciplined healthy lifestyle without consumption of food and beverages containing artificial sugar, sweeteners, E substances, alcohol, nicotine, and drugs, to avoid poisoning. Why? Because, over time and due to a specific genetic background, concentrated sugarcontaining food and beverages, alcohol, and nicotine, cannabis, heroin, LSD etc. weaken, disrupt, and destroy the personality and make one sensitive to become the addicted victim and follower of forms of despotism (politics, power games, religion, food industry, consumerism etc.). In addition, fitness is maintained by regular sports and physical activities. Finally, brain work is sustained by continuous intellectual activities, learning, teaching, and creating and following new ideas (philosophy, science, myth of man studies). All forms of despotism contain valuable content. Thus, you should try to select the valuable ideas and leave out the bad ones. According to this approach, you may foster a tolerant culture for an openminded society (Sir Karl Popper!). Furthermore, the aforementioned aspects will contribute to orchestrate a harmonic, healthy, and happy life incorporating a critical, but tolerant, respectful interaction with your environment! As such, happy surgeons will be better at their job, have fun at doing and prospering. Would you hesitate to become a happy and successful surgeon? A beloved and respected personality? Before following the blind and unhealthy concepts of the majority of our modern civilization, try to individualize for the tailored benefit of your life quality and wellbeing. May these attitudes foster a better life for your families, friends, neighbors, and colleagues. Try to combine, harmonize, respect, tolerate, motivate, and orchestrate. Stay away from manipulation. Greed, envy, and hate are the manifestations of a wicked, weak personality. People with these qualities should see a psychologist to receive professional therapy to reshape their personality. Here you may orchestrate sound music and you may contribute to enrich the garden of flowers, the spectrum of colors for the benefit of the beauty of our globe. It should be borne in mind that we will not be fully capable of overcoming the will to power, of fully overriding the nature of our being, but it would be a great step forward to reach out for the half of it! Or to step out of the negative, destructive aspects of the will to power and foster the productive, nourishing, fruitful, beneficial aspects of the will to power. Help us to design a better world. Morals are the swords cutting apart the roots of our existence. Justify yourself, believe in yourself with respect for the universe. Who would you be without the perception of the moment, the now, the atmosphere? Who? Death overcomes it all, even the will to power. Therefore: enjoy, travel, change, delight, and challenge now! Keep your culture, do not be afraid of the wolf pack (Bob Marley, Jamaica)!

\section{Sincerely,}

Martin Riegler.

Acknowledgements The author is thankful for being allowed to be part of the moment and atmosphere opening an understanding for humility, tolerance, and respect. In addition, the author thanks his parents, family, friends, colleagues, teachers, patients and the entire wonderful motivated team of Springer for their passion and support of the author's project: the myth of man and its manifestation in the form of academic surgery, science, and publishing.

Conflict of interest M. Riegler declares that he has no competing interests. 